Sources of funding:

Danish Research

Councils; Danish

Ministry of Health;

Foundation. Pharmacia

Upjohn sponsored the

nicotine substitution

products.

For correspondence:

Bispebjerg University

Hospital, Copenhagen,

Denmark.

docamm@yahoo.com

A modified version of this abstract appears in ACP

Journal Club.
Director Danielsen's

Dr AM Møller

\section{A preoperative smoking intervention decreased postoperative complications in elective knee or hip replacement}

\author{
Møller AM, Villebro N, Pedersen T, et al. Effect of preoperative smoking intervention on postoperative complications: a \\ randomised clinical trial. Lancet 2002 Jan 12;359:114-7.
}

\section{QUESTION: Does a preoperative smoking intervention reduce postoperative morbidity and mortality in patients having elective knee or hip replacement?}

\section{Design}

Randomised \{allocation concealed\}, blinded (outcome assessor), controlled trial with follow up to discharge.
Setting

3 university affiliated hospitals in Copenhagen, Denmark.
Smoking intervention v usual care in patients having elective knee or hip replacement

$\begin{array}{lcccc}\begin{array}{l}\text { Outcomes to time of } \\ \text { discharge }\end{array} & \begin{array}{l}\text { Smoking } \\ \text { intervention }\end{array} & \begin{array}{l}\text { Usual } \\ \text { care }\end{array} & \text { RRR (95\% Cl) } \neq & \text { NNT (Cl) } \\ \begin{array}{lllll}\text { Postoperative complications } & & & & \\ \hline \text { Any complication } & 18 \% & 52 \% & 65 \%(42 \text { to } 83) & 3 \text { (2 to } 6) \\ \hline \text { Wound related } & 5 \% & 31 \% & 83 \%(48 \text { to } 95) & 4 \text { (2 to } 8) \\ \hline\end{array}\end{array}$

†Abbreviations defined in glossary. $¥ \mathrm{Cl}$ calculated from data in article.

\section{COMMENTARY}

A systematic review by Rice and Stead ${ }^{1}$ has shown the benefits of smoking cessation advice and counselling provided by nurses to their patients. This study by Moller et al adds to the evidence by showing that a smoking cessation programme delivered by a nurse preoperatively reduced the risks of any postoperative complication and wound related complications in patients having elective knee or hip replacement when compared with usual care. The number needed to treat (NNT) of 4 (table) indicates that 4 patients would need to participate in the preoperative smoking cessation programme in order to prevent 1 additional wound related complication. Although an economic analysis was not done, this small NNT suggests that the intervention is likely to lead to cost savings in the healthcare system. Study findings confirm previous research that has shown an increased risk of non-union for smokers after ankle arthrodesis ${ }^{2}$ and the need to abstain from smoking for $>1$ week preoperatively to reduce postoperative complications. ${ }^{3}$

Moller et al also provide insight into shared preoperative decision making between nurses and patients and its effect on patient outcomes during surgery. The positive findings for patients who participated in the nurse delivered preoperative smoking cessation programme resonate with the importance of the nursing role in ensuring the best possible outcomes and quality of care for their patients.

Even in a randomised controlled trial, it is possible to have clinically important differences between groups at baseline, especially when the sample size is small. In this study, fewer patients in the intervention group received general anaesthesia $(50 \%)$ than in the usual care group (63\%). Although not statistically significant, this difference could have contributed to the favourable postoperative complication rates in the intervention group.

Other studies have evaluated preoperative smoking cessation interventions such as written advice. ${ }^{4}$ Clearly, nurses have an important role to play in smoking cessation for the general population and for those scheduled for elective surgery. Given the current economic constraints in the healthcare system, it is wise to restrict these interventions to those that have been shown to be effective, such as the one described in this study.

Ernestine W Murray, RN, MAS Captain, US Public Health Service Senior Health Policy Analyst Agency for Healthcare Research and Quality Rockville, Maryland, USA

1 Rice VH, Stead LF. Nursing interventions for smoking cessation. Cochrane Database Syst Rev 2002;(1):CD001188.

2 Cobb TK, Gabrielsen TA, Campbell DC 2nd, et al. Cigarette smoking and nonunion after ankle arthrodesis. Foot Ankle Int 1994;15:64-7.

3 Chodoff P, Margand PM, Knowles CL. Short term abstinence from smoking: its place in preoperative preparation. Crit Care Med 1975;3:131-3.

4 Munday IT, Desai PM, Marshall CA, et al. The effectiveness of pre-operative advice to stop smoking: a prospective controlled trial. Anaesthesia 1993;48:816-8.

\section{Patients}

120 patients who were scheduled for primary elective hip or knee replacement and were daily smokers. Patients with a weekly alcohol intake $>35$ units were excluded. 108 patients $(90 \%)$ were included in the analysis (median age $65 \mathrm{y}, 57 \%$ women).

\section{Intervention}

At 6-8 weeks before surgery, 60 patients were allocated to the smoking intervention and were offered a weekly meeting with the project nurse. At the first meeting, a Fagerstöm test was done to estimate the patient's nicotine dependence. Test results and patient preference were used to devise a personalised nicotine substitution schedule. Patients were strongly encouraged to stop smoking, but had the option to reduce tobacco consumption by $\geqslant 50 \%$. Smoking status was monitored, and nicotine substitution products were provided free of charge. At subsequent meetings, tobacco consumption was recorded and patients were given advice about smoking cessation or reduction, benefits and side effects, and management of withdrawal symptoms and weight gain. 60 patients were allocated to usual care (little or no information or counselling on smoking).

\section{Main outcome measure}

Postoperative complications (death or postoperative morbidity requiring treatment within 4 wks after surgery).

\section{Main results}

Analysis was by intention to treat. No patients died before discharge. Rates of any postoperative complication and of wound related complications were lower in the smoking intervention group than in the usual care group (table).

\section{Conclusions}

A preoperative smoking intervention was more effective than usual care for reducing rates of any postoperative complication and wound related complications in patients having elective knee or hip replacement. No deaths occurred before discharge.

*Information provided by author. 